\title{
Die Stellung der Augen beim Einschlafen und Aufwachen.
}

Von

W. Henke.

Es finden sich manche Angaben aus alter und neuer Zeit über die Stellung der Augen im Schlafe. Eine sichere Begründung derselben durch Beobachtung kenne ich nicht. Sie wird auch schwer zu liefern sein. Denn wenn man auch die Richtung der Sehachsen wohl finden würde, wenn man einem Schlafenden plötzlich die Augenlider öffnet, so bliebe doch die Stellung der Meridiane unentschieden. Die sonst für die Ermittelung der Stellungen des Auges stets brauchbare Beobachtung der Bilder, welche es von den vor ihm liegenden Dingen giebt, kann man im Schlafe nicht machen. Indessen findet sich hierzu wenigstens beim Beginne oder beim Schwinden der Nervenleitungsunterbrechung, wenn sie sich etwas allmälig vollzieht, bei einem halben Einnicken oder Aufdämmern zuweilen einige Gelegenheit. Wenn man sich mit Gewalt zwingen will, aber auf die Dauer nicht mehr zwingen kann, bei einer langweiligen Lectüre oder Unterhaltung die mïiden Augen offen zu erhalten, kommt es vor, dass, wie auch sonst einzelne Muskelgruppen nach 
einander plötzlich den Nerven den Dienst versagen, so auch die Augenmuskeln, welche die dem Gebrauche des Sehens entsprechende Stellung der Netzhänte exhalten, früher die im Wachen nie nachlassende, zweckmässige Zusammenwirkung aussetzen, als die widerstrebenden Augenlider sinken; oder wenn man behaglich in Bette liegt und von einer schon recht vollen Tagesbeleuchtung allmälig geweckt wird, kommt es vor, dass sich die Lider öffnen, ohne dass zugleich auch die Augen schon fest zum Sehen eingestellt werden. In beiden Fällen erkennt man, wenn man noch oder schon geistig hell genug ist, um die das Sehfeld füllenden Eindrücke zu percipiren, Doppelbilder der vor dem Auge befindlichen Gegenstände. Bei mehrfach auf den Gegenstand gerichteter Aufmerksamkeit ist es mir auch einige Male gelungen, jenen Zustand des IIalbwachens, in welchem die Augenmuskeln noch nicht der zweckmässigen Anleitung ilher Nerven folgen, neben der zur Beobachtung ausreichenden Klarheit des Bewusstseins so lange hinzuhalten, dass ich durch ein vorsichtig geleitetes Verdecken eines Auges mit der Hand noch entscheiden kounte, welches Doppelbild aus dem rechten oder linken Auge stamnte. Das Resultat dieser Beobachtung will ich hier mittheilen.

Das Auffallendste, was wohl Jeder schon zu bemerken Gelegenheit hatte, der einmal mit dem Schlafe gekämpft hat, ist ein seitliches Auseinanderweichen der Doppelbilder, wie man es auch im Wachen willkürlich sehr leicht erhalten kam, wemn man vor nahen Objecten die Augen in die Ferne richtet, und zwar erfolgt es ebenso durch Divergiren. In der einfachen Form, wie man so jeden Augenblick im Wachen Doppelbilder erhalten kann, bleiben dieselben einander im Ganzen parallel, die senkrechten identischen Meridiane der Netzhäute bleiben senkrecht, abgesehen von den kleinen Neigungen zur Seite, 
welche sich aus den Untersuchungen über den verticalen Horopterdurchschnitt von Meissner u. a. ergeben haben, und letztere sind ganz constant und von willkürlichen wie unwillkürlichen Abweichungen frei. Die Doppelbilder, die man in Halbschlafe beobachten kann, sind aber zugleich sehr stark gegen einander geneigt, und zwar die aus dem rechten Auge erhaltenen mit dem oberen Ende nach rechts hin. Hieraus ist leicht abzuleiten, dass die Augen mit den oberen Enden ihrer verticalen Meridiane convergiren. I)enn das Bild eines Punktes, welches sich gerade nach oben vor dem $\Lambda$ uge befindet, ist, wenn er durch das rechte gesehen nach rechts geriuckt scheint, in diesem auf einen nach links vom unteren Theile des senkrechten Meridians gelegenen Netzhautpunkt gefallen; dieser ist also an die Stelle eines sonst gerade nach untenl liegenden, also nach der Seite gerückt; dagegen der obere Theil des Auges nach der Nitte, dem anderen entgegen. Die Augen "hefinden sich also im Einschlafen und Aufwachen im Vergleiche mit der Haltung im Wachen in einer mehr divergirenden und mit der oberen IIälfte nach der Nase hin rotirten Stellung, einer Stellung also, welche, wenn sie durch Muskelzug herrorgebracht gedacht werden sollte, als eine Wirkung der Recti ext. und Obliqui sup. zu bezeichnen wäre.

Damit ist nicht gesagt, dass dies auch die Stellung in völligen Schlafen ist und die bisherigen Angaben über letztere würden damit nicht stimmen. Liese sich dieses entscheiden, so würde davon auch die Deutung des von mir beobachteten Stellungswechsels abhängen. Wäre er nur Anfang und Ende des Ruhezustandes im vollen Schlafe, so würde man seine Frklärung in den elastischen Kräften suchen müssen, welche auf den Augapfel bei nachlassender Action seiner Muskeln Einfluss haben können. Wäre er dagegen nur ein vorübergehender Uebergang von dem Resultate der vollen Muskelaction im Wachen 
zu dem vollen Ruhestande im Schlafe, so läge es sehr nahe, ihn aus einer successiven Lösung und Erneuerung der Leitungsfähigkeit der Nerven zu deuten. Fr würde dann ein vorübergehendes Ueberwiegen der beiden oben genannten Muskeln, der beiden, welche ihre besonderen Bewegungsnerven haben, darstellen und also beweisen, dass die Herrschaft des $N$. oculomotorius über die von ihm abhängigen Muskeln früher einschläft und später aufwacht, als die des trochlearis und abducens. Fs streitet damit nicht, dass in dem Falle, wo es gelingt, obige Beobachtungen anzustellen, auch der vom oculomotorius mit innervirte $\mathrm{M}$. levator palpebrae superioris noch oder schon in Thätigkeit sein muss. Denn dies ist ja auch ein Ausuahmsfall und gerade der Wirkung auf das Offenhalten cles Lides steht sowohl bei Sträuben gegen das Einschlafen, als auch bei Erwachen durch einen Reiz allgemeiner Helligkeit ein besonderer Impuls zur Seite. Für gewöhnlich aber wird eben deshalb jenes Phänomen nicht bemerkt, weil der Augendeckel schon oder noch herabgelassen ist, wenn es sich vollzieht. 